\title{
KAJIAN KEMURNIAN DAN PENGARUH NISBAH PEREAKSI, pH AWAL REAKSI DAN SUHU REAKSI TERHADAP NILAI CMC \& HLB NATRIUM LIGNOSULFONAT
}

\author{
Eric Wirtanto, Michael Lim, Zuhrina Masyithah \\ Departemen Teknik Kimia, Fakultas Teknik, Universitas Sumatera Utara, \\ Jl. Almamater Kampus USU, Medan 20155, Indonesia \\ Email : riq_90@yahoo.co.id
}

\begin{abstract}
Abstrak
Natrium LignoSulfonat (NaLS) merupakan surfaktan hasil sulfonasi lignin isolat dengan menggunakan $\mathrm{NaHSO}_{3}$ sebagai agen pensulfonasi. Penelitian diawali dengan mengisolasi lignin dari cangkang kelapa sawit kemudian dilanjutkan dengan reaksi sulfonasi dengan perbandingan nisbah cangkang kelapa sawit - $\mathrm{NaHSO}_{3}$ (b/b) 1:0,2; 1:0,3; dan 1:0,5 dan $\mathrm{pH} 6,7$, dan 8 pada suhu $85^{\circ} \mathrm{C}$ dan $95^{\circ} \mathrm{C}$. Kemurnian surfaktan NaLS yang dihasilkan pada penelitian ini yaitu sebesar $66,1782 \%$. Nilai CMC yang diperoleh untuk surfaktan NaLS ini berkisar antara 0,014 - 0,052; dimana penurunan tegangan permukaan air berkisar antara 53,63-59,83 dyne/cm, sedangkan nilai HLB yang diperoleh berkisar antara 3,805 - 4,278; yang berarti bahwa surfaktan ini tergolong lipofililk. Karakteristik NaLS yang dihasilkan adalah berwarna cokelat tua, dan larut sempurna dalam air.
\end{abstract}

Kata kunci: cangkang kelapa sawit, lignin, natrium lignosulfonat, sulfonasi

\begin{abstract}
Sodium lignosulphonate (SLS) is a product of isolated lignin sulphonation process using $\mathrm{NaHSO}_{3}$ as sulphonation agent.The research begins with isolated lignin from palm shell amd continued with sulphonation with mass ratio of palm shell lignin - $\mathrm{NaHSO}_{3}(\mathrm{~b} / \mathrm{b})$ of 1:0.2, 1:0.3, and 1:0.5 and initial $\mathrm{pH}$ of 6, 7, and 8 at temperature $85{ }^{\circ} \mathrm{C}$ and $95^{\circ} \mathrm{C}$. The purity of SLS made in this studies was $66,782 \%$. The CMC value of this SLS ranged from 0,014-0,052; while the lowering of surface tension of water ranged from 53,63 - 59,83 dyne/cm. The HLB value ranged from 3,805-4,278, means that this surfactant classified as lipophilic. The resulted SLS was dark brown, and water soluble.
\end{abstract}

Keywords: palm shell lignin, lignin, sodium lignosulphonate, sulphonation

\section{Pendahuluan}

Cangkang kelapa sawit saat ini merupakan salah satu dari sekian banyak limbah yang dihasilkan industri di Indonesia, hal ini tidak terlepas dari status Indonesia sebagai negara penghasil minyak kelapa sawit terbesar kedua setelah Malaysia yang memiliki kapasitas produksi yang terus meningkat tiap tahunnya (2,75\%29,91\%) (Dirjen Perkebunan, 2005). Saat ini, di Indonesia cangkang kelapa sawit sebenarnya juga telah banyak dimanfaatkan misalnya saja sebagai bahan baku pembuatan norit dan asap cair. Namun seiring bertambahnya jumlah limbah cangkang kelapa sawit, maka perlu dicari juga alternatif lain mengenai pemanfaatan cangkang kelapa sawit yang lebih efisien dan memiliki nilai ekonomis yang tinggi. Cangkang kelapa sawit memiliki komposisi lignin yang cukup besar ${ }^{[9]}$. Hal ini menyebabkan dimungkinkannya pemanfaatan cangkang kelapa sawit sebagai bahan baku olahan produk lignin menjadi Natrium Lignosulfonat (NaLS) melalui reaksi sulfonasi. Perumusan masalah dalam penelitian ini adalah bagaimana kemurnian NaLS yang dapat dihasilkan serta bagaimana pengaruh antara nisbah lignin $\mathrm{NaHSO}_{3}, \mathrm{pH}$ dan suhu pada reaksi sulfonasi lignin terhadap nilai critical micelle concentration \& hydrophilic-lipophilic balance NaLS. Tujuan dari penelitian ini adalah untuk mengetahui kemurnian NaLS yang dihasilkan, serta mengamati pengaruh rasio nisbah pereaksi lignin dan $\mathrm{NaHSO}_{3}$ dan $\mathrm{pH}$ awal reaksi terhadap nilai critical micelle concentration \& hydrophilic-lipophilic balance Natrium Lignosulfonat (NaLS) yang dihasilkan.

\section{Teori}

Cangkang sawit merupakan bagian paling keras pada komponen yang terdapat pada kelapa sawit, dikarenakan kandungan lignin di dalamnya yang cukup tinggi yaitu sekitar 29,4\%; serta kandungan selulosa dan hemiselulosanya masingmasing sebesar $27,7 \%$ dan $26,6 \%$; selain itu kadar airnya yang cukup rendah yaitu sebesar $8 \%$. Saat ini pemanfaatan cangkang sawit di berbagai industri pengolahan minyak CPO belum begitu maksimal.Cangkang sawit dapat diolah menjadi 
beberapa produk yang bernilai ekonomis tinggi, yaitu karbon aktif, fenol, asap cair, tepung tempurung dan briket arang.

Lignin adalah suatu polimer yang komplek dengan bobot molekul tinggi yang tersusun atas unit-unit fenilpropana. Yang merupakan komponen rantai panjang yang terbentuk di dalam dinding sel. Struktur dari lignin adalah kompleks, tidak teratur, acak, dan penyusun utamanya dari senyawa aromatik, yang mana menambah elastisitas matrik selulosa dan hemiselulosa ${ }^{[8]}$. Lignin bersifat tidak larut dalam kebanyakan pelarut organik. Pada suhu tinggi, lignin dapat mengalami perubahan struktur dengan membentuk asam format, metanol, asamasetat, aseton, vanilin dan lain-lain. Sedangkan bagian lainnya mengalami kondensasi ${ }^{[1]}$.

Natrium lignosulfonat (NaLS) dapat disintesis dari lignin dengan reaksi sulfonasi yang merupakan reaksi yang melibatkan pemasukan gugus sulfonat ke dalam lignin. Proses sulfonasi pada lignin bertujuan untuk mengubah sifat hidrofilitas dari lignin yang tidak larut dalam air dengan memasukkan gugus sulfonat yang lebih polar dari gugus hidroksil, sehingga akan meningkatkan sifat hidrofilitasnya dan menjadikan lignosulfonat. Dengan demikian penggunaan NaLS menjadi luas ${ }^{[7]}$.

Pemilihan proses sulfonasi tergantung pada banyak faktor, diantaranya yaitu nisbah lignin dan agen sulfonasi, suhu reaksi, waktu atau lama reaksi, $\mathrm{pH}^{[5]}$.

\section{CMC (Critical Micelle Concentration) dan HLB} (Hydrophilic-Lipophilic Balance)

Penambahan surfaktan ke dalam cairan (air) akan menyebabkan turunnya tegangan permukaan cairan tersebut. Setelah mencapai konsentrasi tertentu, tegangan permukaan akan konstan walaupun konsentrasi surfaktan ditingkatkan dan bila ditambahkan terus menerus akan mengagregasi membentuk misel, pada konsentrasi terbentuknya misel inilah yang disebut dengan critical micelle concentration (CMC) ${ }^{[6]}$.

Hydrophilic-Lipophilic Balance dari suatu jenis surfaktan (dalam kasus ini, NaLS) merupakan sebuah ukuran atau nilai dari golongan apakah termasuk hidrofilik atau lipofilik. Penggolongan ini ditentukan dengan perhitungan nilai pada perbedaan area terbentuknya molekul. Nilai HLB juga dapat digunakan dalam penentuan sifat surfaktan, seperti berikut:

HLB $<10$ : lipofilik,

HLB > 10: hidrofilik,

$4 \leq \mathrm{HLB} \leq 8$ : anti-foaming agent,

$7 \leq \mathrm{HLB} \leq 11$ : w/o emulsifier,

$12 \leq \mathrm{HLB} \leq 16:$ o/w emulsifier, ${ }^{[4]}$.

\section{Metodologi Penelitian \\ Bahan dan Alat}

Bahan yang digunakan adalah cangkang kelapa sawit sebagai bahan bakusebagai zat pengekstrak digunakan benzene dan etanol 96\%, sebagai larutan pemasak digunakan etanol 96\%, air dan $\mathrm{NaOH}$, sebagai pengendap lignin dari lindi hitam digunakan $\mathrm{H}_{2} \mathrm{SO}_{4}$, sebagai bahan pensulfonasi digunakan $\mathrm{NaHSO}_{3}$ dan $\mathrm{NaOH}$ dan untuk pemurnian $\mathrm{NaLS}$ dari sisa $\mathrm{NaHSO}_{3}$ yang tidak bereaksi adalah methanol

\section{Proses Pembuatan Serpih Cangkang Bebas Ekstraktif}

Cangkang kelapa sawit dibersihkan, dikeringkan dengan sinar matahari kemudian digiling, kemudian dipisahkan dengan ayakan. Cangkang yang melewati ayakan kemudian dikeringakn di oven pada suhu $60{ }^{\circ} \mathrm{C}$ hingga berat konstan. Kemudian dilakukan proses ekstraksi dengan nmenggunakan benzene : etanol 96\% (2:1 v/v) selama 6 jam. Setelah itu kemudian dikeringkan di oven pada suhu $60{ }^{\circ} \mathrm{C}$ dan diekstraksi lagi dengan air mendidih selama 2 jam.

\section{Proses Isolasi Lignin}

Sebanyak 600 gr cangkang kelapa sawit dimasak dengan larutan $96 \%$ : air (1:1) dengan perbandingan 1:10 (b/v). Dengan menggunakan katalis $\mathrm{NaOH} 10 \%$ berat bahan baku, cangkang kemudian dimasak di dalam digester pada suhu $170^{\circ} \mathrm{C}$ selama 1 jam. Lindi hitam hasil pemasakan kemudian disaring dengan menggunakan kain. Hasil lindi hitam kemudian dititrasi sampai $\mathrm{pH}=2$ dengan asam sulfat $20 \%$ dan didiamkan selama 8 jam. Endapan yang dihasilkan kemudian dipisahkan dari filtrat dengan menggunakan kertas saring, Endapan yang dihasilkan kemudian dilarutkan dengan $\mathrm{NaOH} 1 \mathrm{~N} 100 \mathrm{ml}$. Kemudian disaring lagi dengan menggunakan kertas saring. Filtrat kemudian dicuci dengan asam sulfat $\mathrm{H}_{2} \mathrm{SO}_{4}$ $10 \% \mathrm{v} / \mathrm{v}$ dan diikuti dengan pencucian menggunakan aquadest. Kemudian disaring dengan menggunakan kertas saring dan kemudian dikeringkan dalam oven pada suhu $55{ }^{\circ} \mathrm{C}$ sampai mencapai berat konstan.

\section{Pembuatan Natrium Lignosulfonat}

Sebanyak 5 gr lignin dicampurkan dengan $\mathrm{NaHSO}_{3}$ dengan nisbah lignin - $\mathrm{NaHSO}_{3}(1: 0,2$, 1:0,3 dan 1:0,5) lalu disuspensikan dalam $150 \mathrm{ml}$ air. $\mathrm{pH}$ suspense kemudian dinaikkan menjadi 6,7 dan 8 dengan menggunakan larutan $\mathrm{NaOH} 15 \%$. Campuran selanjutnya direfluks pada suhu $85{ }^{\circ} \mathrm{C}$ dan $95{ }^{\circ} \mathrm{C}$ sambil dilakukan pengadukan dengan magnetic stirrer agar campuran reaksi sempurna dengan pemanas listrik selama 4 jam. 


\section{Pemurnian}

Hasil refluks didestilasi pada suhu $100{ }^{\circ} \mathrm{C}$ untuk menguapkan air, kemudian larutan yang telah pekat disaring dengan corong pemisah untuk memisahkan sisa lignin. Filtrat berupa NaLS yang masih mengandung $\mathrm{NaHSO}_{3}$ (sisa reaksi). Kemudian ditambahkan methanol sambil dikocok kuat sehingga $\mathrm{NaHSO}_{3}$ terendapkan dan disaring dalam corong pemisah. Metanol kemudian diuapkan dengan menggunakan refluks kondensor pada suhu $70{ }^{\circ} \mathrm{C}$. NaLS yang diperolehdikeringkan dalam oven pada suhu $60{ }^{\circ} \mathrm{C}$ hingga berat rendemennya

konstan.

\section{Karakteristik Natrium Lignosulfonat}

Pencirian Warna dan bau. Pencirian wana dan bau dari NaLS dilakukan secara visual.

Uji Kelarutan dalam Air. Sebanyak 0.5 gr NaLS dimasukkan ke dalam gelas ukur $100 \mathrm{ml}$. Kemudian ditambahkan air suling mulai dari $10 \mathrm{ml}$ sampai $50 \mathrm{ml}$. Diamati kelarutan NaLS.

Kemurnian. Sebanyak 0,1 gr NaLS dilarutkan dalam $100 \mathrm{ml}$ aquadest, kemudian dipipet $5 \mathrm{ml}$ larutan tersebut ke dalam gelas ukur berukuran $250 \mathrm{ml}$ dan diencerkan sampai $200 \mathrm{ml}$. $\mathrm{pH}$ larutan diatur menjadi 4 dengan penambahan $\mathrm{NaOH} 0,125 \mathrm{~N}$ atau $\mathrm{HCl} 0,2 \mathrm{~N}$. Larutan tersebut dipindahkan ke dalam labu volumetric $250 \mathrm{ml}$ dan ditetapkan volumenya dengan aquadest. Absorbans larutan diukur pada $232 \mathrm{~nm}$. Tingkat kemurnian ditentukan dengan persamaan berikut :

$\%$ tingkat kemurnian $={ }_{,}=\frac{A 232 \times F P}{\text { Faktor } \times g \times 10}$

Keterangan:

$\mathrm{A}_{232}=$ absorbansi pada $\lambda_{232} \mathrm{~nm}$

$\mathrm{FP}=$ Faktor pengenceran

Faktor = Faktor NLS (35)

Nilai CMC NaLS. Nilai CMC diperoleh dengan memvariasikan konsentrasi $\left(\mathrm{C}_{\mathrm{o}}\right)$ NaLS dalam pelarut air untuk diuji besar tegangan permukaannya $(\gamma)$ dengan tensiometer Du-Nuoy, untuk memperoleh data:

-Faktor Koreksi (FK)

$=\frac{\text { tegangan permukaan aquadest pada } 20^{\circ} \mathrm{C}}{\text { tegangan permukaan aquadest praktek }}$

-Tegangan permukaan $(\gamma)$

$-\gamma$. FK

$-\log \mathrm{C}_{0}$

-Data tersebut kemudian diplotkan ke dalam grafik untuk mendapatkan nilai log CMC-nya (perpotongan grafik dengan sumbu $\mathrm{X}=$ nilai $\gamma$ konstan), dan kemudian akan diperoleh nilai CMC.

Nilai HLB NaLS. Nilai HLB dapat dihitung setelah nilai $\mathrm{CMC}$ diperoleh, dengan persamaan:

$-\mathrm{HLB}=7-0,36 \ln \left(\mathrm{Co} / \mathrm{CW}_{w}\right)$

\section{Hasil dan Pembahasan}

Karakteristik surfaktan NaLS yang dihasilkan untuk kemudian diamati nilai CMC dan HLB-nya antara lain:

\section{Warna dan Bau}

NaLS dari limbah cangkang kelapa sawit ini berbentuk serbuk yang agak kasar dengan warna cokelat tua, namun sedikit lebih terang dibandingkan lignin cangkang kelapa sawit. Perubahan ini terjadi karena adanya gugus sulfonat pada struktur NaLS berupa ikatan rangkap dan juga diperkuat dengan bau belerang pada produk yang dihasilkan. Selain itu, $\mathrm{pH}$ NaLS yang diamati mempunyai nilai 6-7 serta dapat larut dalam air.

\section{Kemurnian}

Untuk mengetahui kemurnian NaLS yang dihasilkan, dapat diuji dengan spektrofotometer UV untuk memperoleh data yang diperlukan untuk kemudian dimasukkan ke persamaan (a), maka didapatkan kemurnian tertinggi untuk surfaktan NaLS pada penelitian ini sebesar $66,1782 \%$. Hasil spektrofotometri UV dapat dilihat pada gambar berikut:

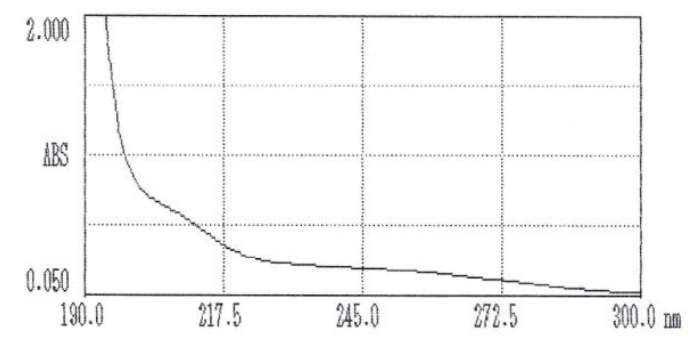

Gambar 1. Hasil Spektrofotometri UV

\section{Nilai CMC \& HLB Natrium Lignosulfonat}

Nilai CMC akan menunjukkan sampai batas mana kemampuan surfaktan untuk menurunkan tegangan permukaan cairan(air). Nilai CMC yang diperoleh berkisar antara 0,014-0,052. Sementara nilai HLB yang diperoleh berkisar antara 3,805 4,278; dimana nilai ini menunjukkan golongan surfaktan.

\section{Hubungan Nisbah Pereaksi Lignin - $\mathrm{NaHSO}_{3}$, pH, dan Suhu terhadap Nilai CMC}

Dapat dilihat hubungan nisbah pereaksi lignin - $\mathrm{NaHSO}_{3}$ terhadap nilai CMC dimana nilai CMC yang diperoleh cenderung meningkat untuk setiap kenaikan nisbah pereaksi, seperti yang ditunjukkan pada grafik berikut:

dimana $\mathrm{Cw}=$ nilai $\mathrm{CMC} ; \mathrm{Co}=100-\mathrm{Cw}$ 


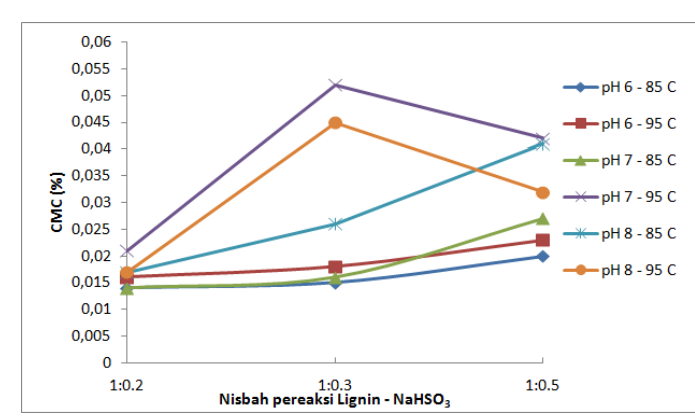

Gambar 2. Nilai CMC NaLS Berdasarkan Nisbah Pereaksi Lignin : $\mathrm{NaHSO}_{3}$

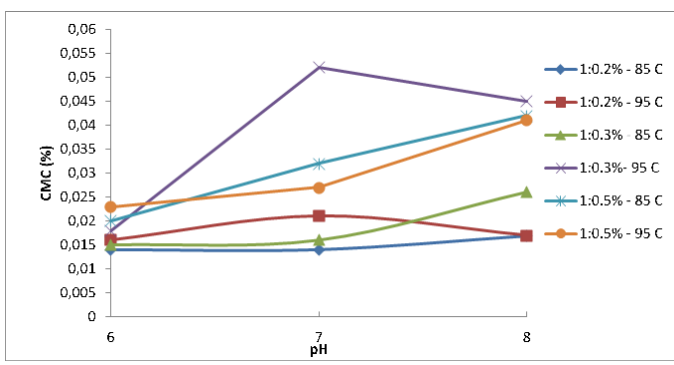

Gambar 3. Nilai CMC NaLS Berdasarkan pH

Walaupun ada penurunan pada dua titik nisbah 1:0,5 (untuk kondisi $\mathrm{pH} 7$; suhu $95^{\circ} \mathrm{C}$, dan $\mathrm{pH} 8$; suhu $95^{\circ} \mathrm{C}$ ). Hal ini disebabkan oleh kejenuhan pada gugus di dalamnya, seperti yang ditunjukkan juga pada pengaruh nisbah pereaksi terhadap berat rendemen ${ }^{[3]}$. Begitu juga penurunan yang terjadi pada perbedaan kondisi $\mathrm{pH}$ (untuk kondisi nisbah 1:0,2; suhu $95^{\circ} \mathrm{C}$, dan nisbah 1:0,3; suhu $95^{\circ} \mathrm{C}$ ). Nilai CMC yang diperoleh untuk surfaktan NaLS ini berkisar antara 0,014 - 0,052; dimana penurunan tegangan permukaan air berkisar pada nilai 53,63 - 59,83 dyne/cm (tegangan permukaan air mula-mula yaitu 72 dyne/cm).

Kedua grafik di atas apabila kita amati, dapat dilihat juga bahwa pada setiap kenaikan suhu reaksi yang dikondisikan $\left(85^{\circ} \mathrm{C}\right.$ dan $\left.95^{\circ} \mathrm{C}\right)$, maka nilai CMC surfaktan yang dihasilkan juga cenderung mengalami peningkatan, dimana ketika terjadi peningkatan suhu maka dapat menyebabkan peningkatan energi akitivasi. Hal ini menyebabkan banyak molekul yang memiliki energi pengaktif sehingga semakin banyak tumbukan antar molekul yang terjadi dan terus berlanjut terjadi dalam reaksi sulfonasi. Semakin banyak tumbukan antar molekul akan menyebabkan berat rendemen yang juga semakin tinggi ${ }^{[10]}$, hal ini tentunya berimbas kepada semakin baiknya kemampuan menurunkan tegangan permukaan surfaktan sehingga nilai CMC-nya pun meningkat.
Maka dapat disimpulkan semakin meningkatnya nisbah pereaksi lignin - $\mathrm{NaHSO}_{3}$ serta $\mathrm{pH}$ reaksi, semakin meningkat pula nilai CMC yang diberikan surfaktan. Surfaktan dinilai semakin baik jika memiliki nilai CMC yang semakin meningkat ${ }^{[10]}$.

Pada kondisi $\mathrm{pH} 7-95^{\circ} \mathrm{C}$ dan pada $\mathrm{pH}$ 8-95 ${ }^{\circ} \mathrm{C}$, nilai CMC NaLS menurun pada saat nisbah lignin $-\mathrm{NaHSO}_{3}$ 1:0,5\% serta nisbah $1: 0,2-95{ }^{\circ} \mathrm{C}$ dan 1:0,3-95 ${ }^{\circ} \mathrm{C}$, ini disebabkan karena telah terjadi kejenuhan atau kemampuan masuknya gugus sulfonat menggantikan gugus hidroksil ($\mathrm{OH})$ pada lignin telah mencapai maksimum.

\section{Data Nilai HLB NaLS}

Harga Hidrophylic-Lipophylic Balance (HLB) yang diperoleh dapat dilihat pada tabel nilai Hidrophylic-Lipophylic Balance atau HLB (Tabel 1).

Tabel 1. Data Nilai HLB NaLS

\begin{tabular}{|c|c|c|c|}
\hline No & $\begin{array}{c}\text { Nisbah Pereaksi Lignin }-\mathrm{NaHSO}_{3} \\
(\mathrm{~b} / \mathrm{b})\end{array}$ & pH-Suhu & HLB \\
\hline \multirow{6}{*}{1.} & \multirow{6}{*}{$1: 0,2$} & $6-85^{\circ} \mathrm{C}$ & 3,805 \\
\hline & & $7-85^{\circ} \mathrm{C}$ & 3,805 \\
\hline & & $8-85^{\circ} \mathrm{C}$ & 3,875 \\
\hline & & $6-95^{\circ} \mathrm{C}$ & 3,853 \\
\hline & & $7-95^{\circ} \mathrm{C}$ & 3,951 \\
\hline & & $8-95^{\circ} \mathrm{C}$ & 3,875 \\
\hline \multirow{6}{*}{2.} & \multirow{6}{*}{$1: 0,3$} & $6-85^{\circ} \mathrm{C}$ & 3.830 \\
\hline & & $7-85^{\circ} \mathrm{C}$ & 3,853 \\
\hline & & $8-85^{\circ} \mathrm{C}$ & 4,028 \\
\hline & & $6-95^{\circ} \mathrm{C}$ & 3,896 \\
\hline & & $7-95^{\circ} \mathrm{C}$ & 4.278 \\
\hline & & $8-95^{\circ} \mathrm{C}$ & 4.226 \\
\hline \multirow{6}{*}{3.} & \multirow{6}{*}{$1: 0,5$} & $6-85^{\circ} \mathrm{C}$ & 3,934 \\
\hline & & $7-85^{\circ} \mathrm{C}$ & 4,042 \\
\hline & & $8-85^{\circ} \mathrm{C}$ & 4,192 \\
\hline & & $6-95^{\circ} \mathrm{C}$ & 3,984 \\
\hline & & $7-95^{\circ} \mathrm{C}$ & 4,201 \\
\hline & & $8-95^{\circ} \mathrm{C}$ & 4,103 \\
\hline
\end{tabular}

Dari nilai-nilai HLB yang diperoleh, yaitu berkisar pada 3,805 hingga 4,278 maka dapat disimpulkan bahwa surfaktan NaLS ini tergolong surfaktan lipofilik dan cocok digunakan sebagai anti-foaming agent (HLB $<10=$ lipofilik, HLB 4$8=$ anti-foaming agent $)^{[4]}$.

\section{Kesimpulan}

Cangkang kelapa sawit dapat dijadikan sebagai alternatif dalam pembuatan Natrium Lignosulfonat karena hasil sulfonasi lignin cangkang kelapa sawit berupa Natrium Lignosulfonat yang diperoleh telah sesuai dengan karakteristik yang dijual di pasaran

Hasil kajian menunjukkan kemurnian tertinggi yang diperoleh yaitu sebesar $66,1782 \%$ dari NaLS yang dihasilkan.

Nilai CMC meningkat seiring peningkatan nisbah pereaksi, $\mathrm{pH}$, serta suhu reaksi. Peningkatan 
nilai CMC ini juga menyebabkan meningkatnya nilai HLB surfaktan NaLS. Kondisi terbaik diperoleh ketika perbandingan nisbah pereaksi 1:0,3; pH 7; dan suhu $95{ }^{\circ} \mathrm{C}$ dengan nilai $\mathrm{CMC}$ sebesar 0,052 dan nilai HLB 4,278. Sementara dari rentang nilai HLB $(3,805$ - 4,278) didapatkan bahwa surfaktan NaLS ini tergolong lipofilik dan merupakan anti-foaming agent. Karakteristik NaLS yang dihasilkan, mempunyai warna cokelat tua, larut dalam air.

\section{Daftar Pustaka}

[1] Heradewi, Isolasi lignin lindi hitam dari pemasakan organosolv serat tandan kosong kelapa sawit. Tesis. Fakultas Teknologi Pertanian Institut Pertanian Bogor, 2007.

[2] Ismiyati, Pembuatan Natrium Lignosulfonat berbahan dasar ligniisolate tandan kosong kelapa sawit: Identifikasi dan uji kinerjanya sebagai bahan pendispersi. Jurnal. Program studi Teknik Kimia, Universitas Muhammadiyah Jakarta, 2009.

[3] Syahbirin Gustini, Pengaruh Nisbah Pereaksi (lignin Eucalyptus - Natrium Bisulfit) dan $p H$ awal reaksi terhadap karakteristik Natrium Lignosulfonat. Jurnal. Institut Pertanian Bogor, 2009.

[4] Anonim, Hydrophilic - Lipophilic Balance. wikipedia.org/wiki/Hydrophiliclipophilic_balance,201, diakses tanggal 01 Mei 2012

[5] Foster N. C, Sulfonation and Sulfation Processes. The Chemithon Corporation, www.chemithon.com, 1997, diakses tanggal 23 April 2012

[6] Wahyu, Kimia Permukaan: Surfaktan, duniawahyu.blogspot.com, diakses tanggal 01 Mei 2012

[7] Collepardi M, Chemical Admixtures Today. Proceedings of Second International Symposium on Concrete Tecnology for Sustainable February - Development with EmpHasis on Infrastructure; Ponzano Veneto (Italy), 27 February-3 March 2005. hlm 527-541

[8] Douglas CJ., Phenylpropanneoid metabolism and lignin brosynthesis : from weed to trees.Trends Plant Sci. 1:171-178, 1996.

[9] Suhardiyono, L, Tanaman Kelapa, Budidaya dan Pemanfaatannya, Penerbit Kanisius, Yogyakarta, 153-156, 1988.

[10] Sykes P, A Guidebook to Mechanism in Organic Chemistry. 1989. 